\title{
O Herbário IBGE
}

\author{
Leonardo Lima Bergamini; \\ Mariza Alves de Macedo Pinheiro; \\ Marina de Lourdes Fonseca Resende; \\ Luciano de Lima Guimarães; \\ Betânia Tarley Porto de Matos Góes \\ Insituto Brasileiro de Geografia e Estatística - IBGE
}

Resumo

Os desafios ambientais atuais demandam conhecimento científico sobre a biodiversidade para orientação de políticas públicas. Coleções biológicas são um repositório permanente e acessível e documentam uma vasta gama de dados valiosos, exercendo um papel central na produção desse conhecimento. Neste trabalho apresenta-se o Herbário IBGE, fundado em 1977 e localizado em Brasília. Seu acervo, com mais de 83.000 exsicatas e 3.500 amostras diversas, é bem representativo da flora do Cerrado e encontra-se quase totalmente digitalizado e acessível através da internet. Em suas 4 décadas, o Herbário IBGE tem participado dos esforços colaborativos para compreender, conservar e usar de modo sustentável a diversidade de plantas, participando de projetos regionais e nacionais que amparam políticas em diferentes níveis.

Palavras-chave: Acervo, biodiversidade, banco de dados, tipos nomenclaturais, botânica

\begin{abstract}
The current environmental challenges demand scientific knowledge on biodiversity for public policy guidance. Biological collections are a permanent and accessible repository and document a wide range of valuable data, playing a central role in the production of this knowledge. This paper presents the IBGE Herbarium, founded in 1977 and located in Brasilia. Its collection, with over 83,000 exsiccates and over 3,500 samples of various kinds, is well representative of the Cerrado flora and is almost completely digitized and accessible through the internet. In its 4 decades, the IBGE Herbarium has taken part in collaborative efforts to understand, conserve and sustainably use plant diversity, participating in regional and national projects that support policies at different levels.
\end{abstract}

Key words: collection, biodiversity, database, nomenclatural types, botany

A constatação da profundidade e extensão das mudanças causadas pela atividade humana sobre os sistemas naturais da Terra tem levado à proposta de denominar a atual época geológica como Antropoceno (Crutzen e Stoermer, 2000). Paralelamente a essa percepção, existe um reconhecimento cada vez mais amplo de que a vida e o bem-estar humanos são intimamente dependentes da manutenção da natureza e sua biodiversidade, tanto por seu valor intrínseco, quanto pelos valores culturais e materiais derivados dos serviços ecossistêmicos que a biodiversidade provê. Os impactos causados pela crescente demanda de recursos pela população humana e pelas alterações ambientais que essa demanda acarretou têm levado a uma acelerada erosão da diversidade biológica em todos os níveis de organização seja em escala local, regional 
ou global (Millenium Assessment Board 2005). Mudanças na cobertura e uso da terra, introdução de espécies exóticas invasoras e mudanças climáticas estão entre as principais ameaças à biodiversidade e, caso não sejam enfrentadas, colocarão em grave risco o funcionamento dos ecossistemas que suportam a vida humana na terra (IPBES 2018). O enfrentamento eficaz dessas ameaças depende da tomada urgente de ações cientificamente embasadas, fundamentadas em diagnósticos e monitoramento dos sistemas naturais que permitam uma gestão adaptativa dos recursos naturais e se valham das melhores informações disponíveis. A produção de informações adequadas é, portanto, indispensável, tanto como subsídio para o monitoramento de compromissos internacionais como para a orientação de políticas em nível nacional e local, de modo a garantir, através de uma melhor convivência entre a humanidade e a natureza, um bom futuro para todos.

Ao exercer seu papel como repositório permanente e acessível de exemplares biológicos, as coleções biológicas exercem um papel central na produção de informações sobre biodiversidade. Seus acervos documentam uma vasta gama de dados valiosos, como características morfológicas, químicas e genéticas dos indivíduos preservados, além de observações obtidas durante o evento de coleta, como a localização, data, descrição do ambiente, associações entre espécies, etc. Enquanto centros de pesquisa e ensino, as coleções biológicas propiciam material de estudo para diferentes áreas da biologia, como pode ser evidenciado pela produção científica a elas vinculada. Um levantamento recente, realizado para as Coleções Biológicas do Instituto von Humbolt, da Colômbia, mostra que o material conservado na instituição fomentou a produção de 628 artigos científicos entre 1968 e 2015, com mais de 7500 citações (Aberláez-Cortés et al. 2017). Outro exemplo do potencial de pesquisa fornecido por coleções biológicas pode ser observado na produção associada à Coleção de Aves do Museu da Universidade do Alaska, com impacto equivalente àquele de um ganhador do prêmio nobel em física (Winker e Withrow, 2013) e quase 5.000 citações nos últimos 5 anos $^{1}$.

No campo da taxonomia e sistemática, as coleções fornecem a infraestrutura central para a descrição de novas espécies, garantindo a conservação dos exemplares consultados no processo da descrição taxonômica, conhecidos como tipos nomenclaturais. Considerando o grande número de espécies ainda por descobrir e as alarmantes taxas de perda de habitat, sobretudo nas regiões tropicais, o aumento na capacidade das coleções em processar e disponibilizar os espécimes é fundamental. Entre 1990 e 2006, por exemplo, apesar do esforço amostral considerado baixo (0,59 coletas por $\mathrm{km}^{2}$, Sobral e Stehmann, 2009), foram descritas no Brasil 2875 espécies de angiospermas (Sobral e Stehmann, 2009), em uma média de 170 espécies novas por ano. Além disso, ainda existe um descompasso entre a coleta inicial de exemplares e o estudo taxonômico detalhado dos mesmos, devido à carência de pessoal especializado. Metade das espécies descritas

\footnotetext{
${ }^{1}$ Disponível em: <https://scholar.google.com/citations?user=EbOuSfwAAAAJ\&hl=en>.
} 
entre 1970 e 2010 passaram mais de 20 anos como material não examinado em herbários (Bebber et al. 2010). Isso ocorre, principalmente, devido ao subdimensionamento de pessoal nos herbários, o que faz com que o tempo de processamento do material se estenda, e também à grande carência de especialistas em muitos grupos de plantas. Estima-se que existam ainda mais de 70.000 espécies desconhecidas de plantas a descrever, sendo que entre $47 \%$ e $66 \%$ dessas espécies provavelmente já se encontram depositadas em herbários (Bebber et al. 2010).

Além de servir de base para o conhecimento taxonômico e documentar a ocorrência das espécies ao longo do tempo e do espaço, os exemplares de coleções podem ser utilizados em diversos tipos de estudos. A análise dos dados morfológicos a partir dos espécimes de coleções botânicas, por exemplo, pode gerar informações sobre a adaptação a diferentes condições ao longo da distribuição geográfica das espécies (McAllister et al. 2018). Os dados históricos representados nos acervos também são ferramentas valiosas na documentação de mudanças temporais como, por exemplo, declínios na população de espécies (Shaffer, Fisher e Davidson, 1998, Bartomeus et al. 2018) ou respostas da fenologia das plantas a mudanças climáticas (Park et al. 2018). Através da análise de vestígios deixados nas plantas, é possível usar os exemplares para o estudo de interações inseto-planta, como demostrado pelo estudo das mudanças nas taxas de herbivoria em uma espécie invasora no Canadá entre 1883 e 2015 (Beaulieu, Lavoie e Proulx, 2018). As informações obtidas através das análises da distribuição histórica de organismos também são úteis na avaliação do estado de conservação (Lughadha et al. 2018). Considerando também coleções vivas, como arboretos ou coleções de micro-organismos, o potencial de produção de informação é ainda maior (Perez et al. 2018).

O papel central das coleções biológicas no ciclo de produção de informações sobre biodiversidade tem sido cada vez mais reconhecido, assim como a importância desse conhecimento para enfrentar os crescentes desafios do Antropoceno (Meineke et al. 2018). Esse reconhecimento também tem sido acompanhado de mudanças mais amplas no modo como o compartilhamento de informações é visto, a partir, por exemplo, de novas práticas de citação das fontes de dados, que permitem creditar o trabalho que os autores dispendem na disponibilização dos dados primários (Escribano et al. 2018) levando a um crescimento na cultura de dados abertos. A partir dos compromissos assumidos na Convenção Sobre a Diversidade Biológica em 1992, a importância das coleções biológicas tem sido evidenciada nacionalmente (Marinoni e Peixoto, 2010) e grandes esforços internacionais tem sido empreendidos para a maior acessibilidade dos acervos, através da digitalização e compartilhamento online dos dados das coleções. Todos esses avanços recentes têm propiciado uma crescente integração entre as instituições produtoras de informação sobre biodiversidade, formando uma complexa "Paisagem da Informática da Biodiversidade" (Bingham et al. 2017) e levando as coleções biológicas a uma nova geração (Schindel e Cook, 2018), em que a 
integração entre diferentes coleções permite o desenvolvimento de pesquisas interdisciplinares de interações e processos complexos.

No Brasil, iniciativas de informatização ganharam força em meados dos anos 2000 (Kury et al. 2006), e desde então, grandes avanços têm sido feitos (Nelson e Ellis, 2018). Atualmente, mais de 14 milhões de registros de ocorrências de espécies no Brasil estão disponíveis online, concentrados no Sistema de Informação sobre a Biodiversidade Brasileira (SIBBr), do MCTIC, que tem como objetivo consolidar uma infraestrutura nacional de dados e conteúdos em biodiversidade. O SIBBr integra uma rede global através da Plataforma Global de Informações em Biodiversidade (Global Biodiversity Information Facility - GBIF - https://www.gbif.org/), que concentra e disponibiliza mais de 1 bilhão de registros de ocorrência provenientes de cerca de 1200 instituições do mundo. Cada vez mais esses dados têm sido usados para a produção de avaliações sobre o estado da biodiversidade (Ponder et al. 2001, Graham et al. 2004), assim como na elaboração de estatísticas e indicadores úteis no planejamento territorial (Ferrier 2002, Hoskins et al. 2019).

Contribuindo para esse esforço de sistematização de dados sobre meio ambiente e recursos naturais (Brasil, 1973), o IBGE criou em 1975 a Reserva Ecológica do IBGE, uma área protegida de interesse científico (Ribeiro 2011, Takahashi et al. 2019 - neste volume) localizada em Brasília. Como forma de apoiar a execução do plano de pesquisas da Reserva Ecológica do IBGE foram fundadas na área, também no final da década de 70, as coleções de referência para os principais grupos de plantas e animais inventariados desde o início das coletas em sua área e no Bioma Cerrado: Herbário IBGE e Coleções Zoológicas. Em 1986, com a incorporação do projeto RADAMBRASIL ao IBGE, o Herbário RADAMBRASIL (HRB), localizado em Salvador, também passou a ser administrado pelo IBGE (Jost 2015). Os dois Herbários são registrados no Index Herbariorum, um cadastro mantido pelo Jardim Botânico de Nova York que reúne informações sobre as principais coleções botânicas do mundo e, juntos, abrigam mais de 140 mil exemplares de plantas de todo o país. Neste trabalho será apresentado o histórico e serão exemplificadas algumas das contribuições realizadas pelo Herbário do IBGE que, ao longo de seus mais de 40 anos, se consolidou como um importante nó na rede colaborativa de coleções botânicas brasileiras.

\section{Hebário IBGE - Histórico}

Desde que assumiu a responsabilidade patrimonial pela área da Reserva (RECOR), no Distrito Federal, o IBGE já previa entre seus objetivos, a destinação da área à pesquisa da flora e fauna sob coordenação do Departamento de Geografia. Já no final da década de 70 , alguns pesquisadores renomados da área de botânica e zoologia foram convidados a implantar e executar os primeiros projetos científicos na área. Cientes da importância das coleções de referência para a 
validação das informações sobre a biodiversidade, foi fundado em 1977 o Herbário IBGE. As primeiras 1000 duplicatas foram doadas pelo seu fundador Eng ${ }^{\circ}$ Agrônomo Ezechias Paulo Heringer, então chefe do Departamento de Pesquisas Ecológicas (DERPE) do IBGE-DF, sendo a bióloga Roberta Cunha de Mendonça sua primeira curadora. Iniciou-se então um intenso programa de coleta que se concentrou primeiramente na área da Reserva Ecológica do IBGE e posteriormente, na região da Bacia do Rio São Bartolomeu2 (Fonseca e Guimarães, 2015). Esse esforço resultou, já nos quatro primeiros anos, em um montante de 40 mil amostras coletadas, sendo 8000 incorporadas à coleção e as demais enviadas em intercâmbio para outros herbários. Em 1980, o Herbário IBGE foi oficialmente registrado na International Association for Plant Taxonomy (IAPT) sob a sigla IBGE (Holmgren e Keuken, 1980). Atualmente integra a Rede Brasileira de Herbários e o Index Herbariorum, onde seus dados são atualizados, a cada seis meses e uma vez ao ano, respectivamente.

Inicialmente, assim como o plano de pesquisas da RECOR, as atividades do Herbário estavam vinculadas ao Programa Institucional "Fauna e Flora - FAUFL", que era composto por uma série de Cadastros de Informações sobre a Biodiversidade Nacional. Mas o acervo foi enriquecido a partir de outros projetos importantes como Biogeografia do Bioma Cerrado, Plano de Manejo da Bacia do Taquara-DF, Impacto do Fogo sobre a Flora e a Fauna do Cerrado, Projeto Sistematização, do próprio IBGE, Levantamento Florístico das Áreas-Núcleo Reserva da Biosfera do Cerrado e Levantamento Florístico do Estado do Tocantins, dos quais é depositário, entre outros projetos realizados por estudantes e pesquisadores de instituições parceiras. Mais recentemente, a atuação do Herbário se estendeu para as demandas institucionais da Diretoria de Geociências do IBGE e outros Planos e Programas Federais em escala nacional.

Assim, ao longo dessas quatro décadas, ao alinhar-se com os compromissos assumidos pela instituição de prover uma base de dados fundamentais sobre a biodiversidade, o Herbário IBGE ampliou sua atuação, por meio de diversas colaborações que tem resultado em melhor aproveitamento dos recursos, aprimoramento dos processos e disseminação do conhecimento. Tais desafios além de impulsionar a sua produtividade tem contribuído de forma sinérgica para fortalecer as parcerias e vínculos institucionais e para torná-lo uma "coleção de referência" sobre a biodiversidade regional.

\footnotetext{
O Rio São Bartolomeu, é o maior rio do Distrito Federal, formado pela confluência dos rios Pipiripau e Mestre D'Armas. Recebe águas do Rio Paranoá e depois segue pelo estado de Goiás, formando a bacia do Corumbá.
} 


\section{Infraestrutura}

O Herbário IBGE ocupa atualmente uma área de $500 \mathrm{~m}^{2}$ climatizada, mantendo a temperatura em torno de $20^{\circ}$ e unidade do ar em até 55\%. Possui 220 armários de aço para herbário, 1 microscópio estereoscópio, 3 freezers, 3 estufas elétricas, para secagem de material botânico e 10 computadores que atendem também às coleções zoológicas (Figura 1).

A dinâmica de funcionamento do herbário é de responsabilidade de sua administração (curadoria e equipe técnica e de apoio), que visa efetivar harmonicamente as várias etapas da coleta botânica à entrada do exemplar na coleção. O incremento da coleção, se faz através de um programa constante de coleta no Bioma Cerrado desenvolvido pelos técnicos do IBGE e parceiros. Antes de serem incorporadas ao acervo, as plantas devem ser preparadas e tratadas segundo técnicas específicas (herborização). No ato da coleta é feita a identificação preliminar. Em seguida, as amostras são prensadas e secas em estufa. Depois, são costuradas em cartolina de tamanho padronizado e as informações sobre a planta são registradas em uma etiqueta. A esse exemplar devidamente preparado e etiquetado dá-se o nome de exsicata. Do material coletado são retiradas duplicatas para intercâmbio científico como doações e permutas. As exsicatas prontas são registradas (tombadas), informatizadas, tratadas e incorporadas à coleção. A desinfecção de todo o material incorporado à coleção é feita através de congelamento no freezer a uma temperatura de $-28{ }^{\circ} \mathrm{C}$ durante 72 horas. Ao final de cada ano é feita também uma fumigação química (fosfeto de alumínio) para evitar o ataque de insetos.
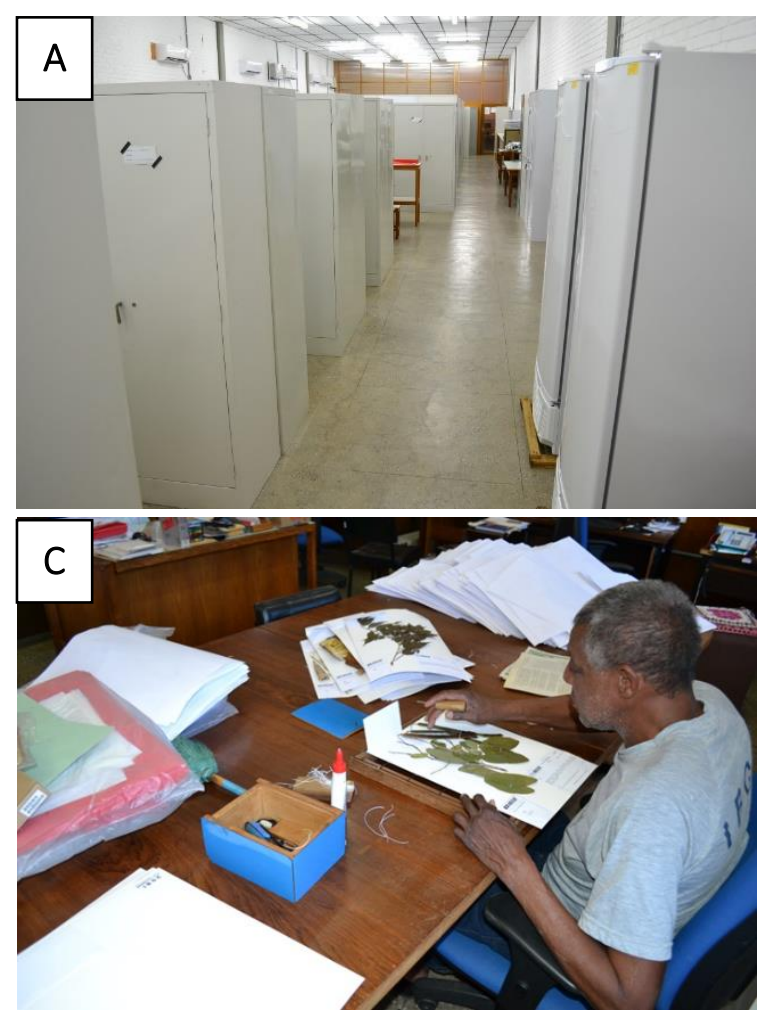

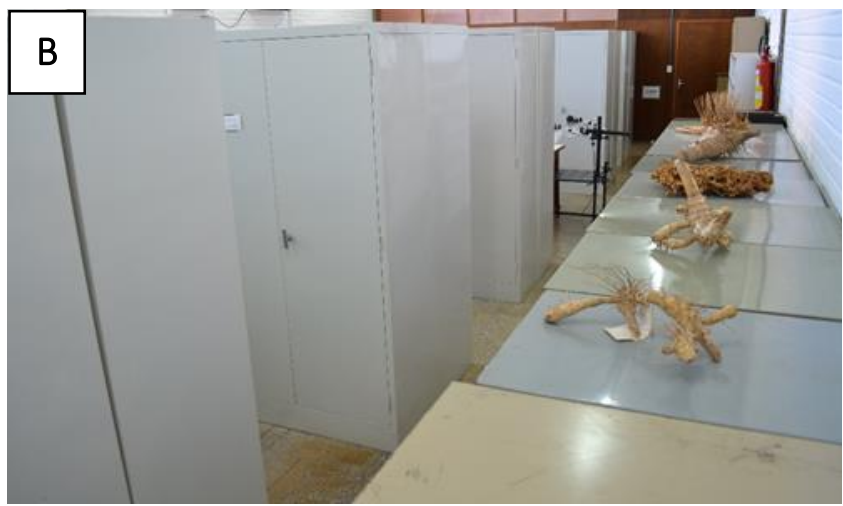

Figura 1 - Visão geral do herbário: A) Sessão das Eudicotiledôneas, Gimnospermas, Samambaias e Licófitas, B) Sessão das Monocotiledôneas, Briófitas, Micoteca, Carpoteca e coleção Dendrológica. C) Processo de montagem das exsicatas. 


\section{Acervo}

O Herbário IBGE tem como finalidade ser depositário da documentação científica da biodiversidade vegetal da região do cerrado. Devido à dinâmica de coleta e de identificação científica do material coletado, o acervo do IBGE é considerado um dos melhores do Brasil dentro da sua área de atuação, e possui uma das melhores coleções de gramíneas desse bioma. Essa excelência tem permitido avanços para o conhecimento da diversidade de plantas do Cerrado e contribuído para a formação de novos pesquisadores, pois além de receber estagiários para treinamento de técnicas de coleta e manejo da coleção botânica, seu acervo tem sido fonte para um elevado número de pesquisas científicas e trabalhos acadêmicos, além do apoio decisivo para a elaboração de políticas públicas de conservação do Bioma (Ribeiro, 2011).

Atualmente, o acervo conta com mais de 83.000 exsicatas e 3.549 amostras diversas (Quadro 1, Gráfico 1). Para facilitar o manejo das exsicatas, embora o sistema de classificação adotado seja o APG IV (APG, 2016), as famílias são dispostas em ordem alfabética, assim como os gêneros dentro de cada família e as espécies dentro dos gêneros. Os armários são divididos em grandes grupos: Eudicotiledôneas, Monocotiledôneas, Gimnospermas e Pteridófitas. Há ainda armários exclusivos para os Tipos Nomenclaturais. A coleção de Angiospermas é bem representativa da flora brasileira, com exemplares de $88 \%$ das famílias reconhecidas para o Brasil, e uma média de $62 \%$ dos gêneros por família (calculado para as famílias com pelo menos 10 gêneros) e de $26 \%$ das espécies por gênero (calculado para os gêneros com pelo menos 10 espécies). Dentre as 78 mil exsicatas informatizadas até o momento, cerca de 91\% estão determinadas ao nível específico ou infraespecífico e mais de $74 \%$ dos registros possuem coordenadas geográficas associadas (coletadas no ponto da amostragem ou inferidas a partir das informações da localidade). Apesar da maior parte dos exemplares ser proveniente do Cerrado, especialmente dos estados de GO, DF, TO, MG e BA, materiais provenientes dos demais estados do Brasil também estão presentes na coleção (Mapa 1), em sua maioria recebidos através de intercâmbio. 


\begin{tabular}{|c|c|c|c|c|}
\hline \multirow{5}{*}{$\begin{array}{c}\text { Plantas } \\
\text { vasculares }\end{array}$} & \multirow{2}{*}{ Angiospermas } & Eudicotiledôneas & 180 famílias & Leguminosas, ipês, etc. \\
\hline & & Monocotiledôneas & 37 famílias & Gramíneas, orquídeas, etc. \\
\hline & \multicolumn{2}{|l|}{ Gimnospermas } & 8 famílias & Pinheiros \\
\hline & \multicolumn{2}{|c|}{ Tipos Nomenclaturais } & $\begin{array}{l}354 \text { exemplares, } \\
183 \text { espécies e } 2 \\
\text { variedades }\end{array}$ & - \\
\hline & \multicolumn{2}{|c|}{ Samambaias e Licófitas } & 29 famílias & Samambaias, avencas \\
\hline \multirow{2}{*}{$\begin{array}{l}\text { Coleções } \\
\text { Correlatas }\end{array}$} & \multicolumn{2}{|c|}{ Amostras dendrológicas } & 375 espécimes & Madeiras \\
\hline & \multicolumn{2}{|l|}{ Carpoteca } & 600 espécimes & Frutos e Sementes \\
\hline \multirow{2}{*}{ Outros } & \multicolumn{2}{|l|}{ Briófitas } & 374 espécimes & Musgos \\
\hline & \multicolumn{2}{|c|}{ Amostras micológicas } & 2200 espécimes & Fungos \\
\hline
\end{tabular}

Quadro1 - Composição da coleção botânica (Herbário IBGE).

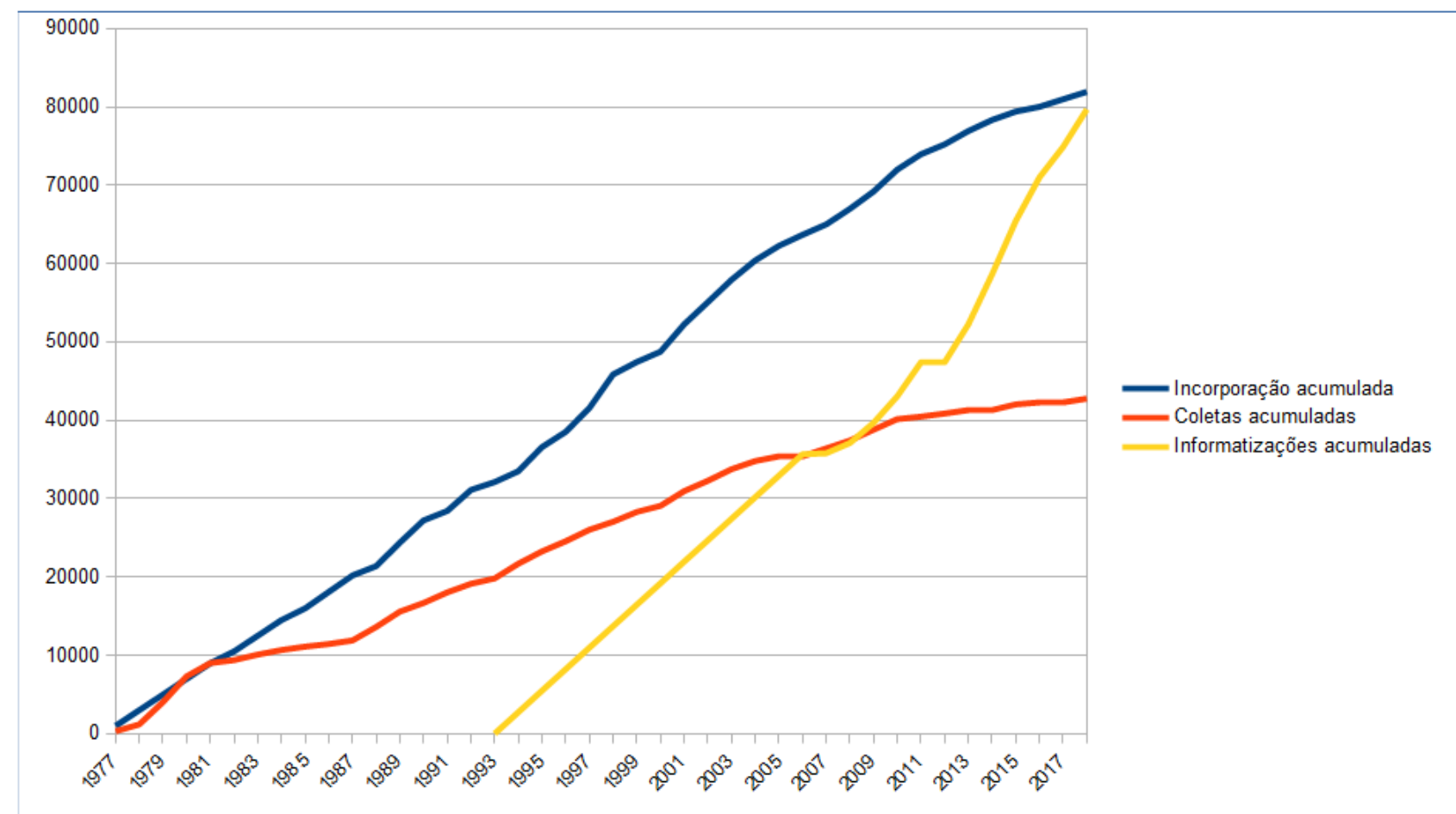

Gráfico 1 - Evolução do acervo do Herbário IBGE ao longo de 41 anos - 1977 - 2018. O número de incorporações anuais anteriores a 1987 e o número de informatizações entre 1994 e 2006 são aproximados. 


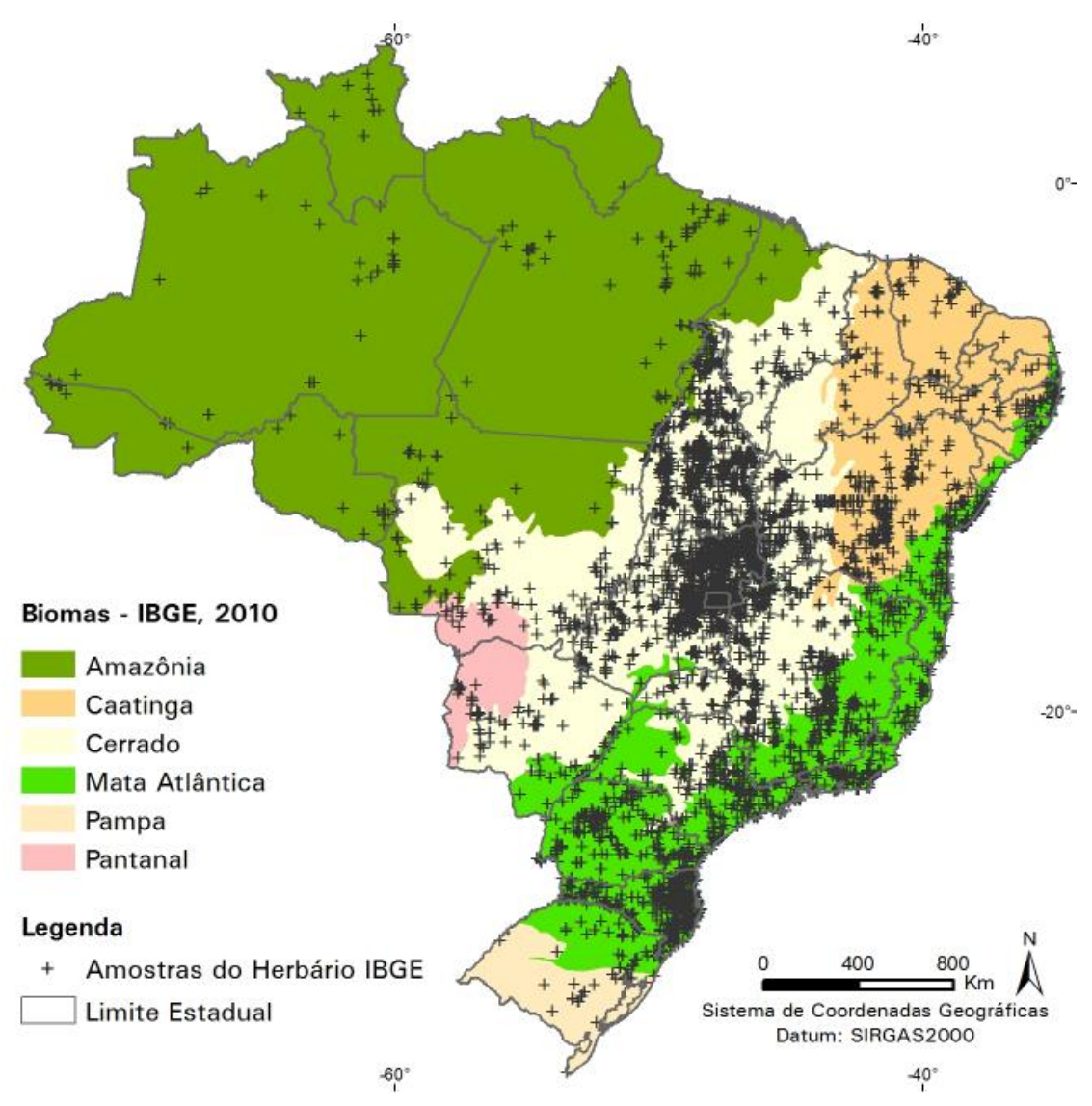

Mapa 1 - Localização geográfica das amostras do Herbário IBGE. Amostras do exterior não estão representadas.

Além do material botânico, a coleção tem à sua disposição uma biblioteca com várias obras clássicas como a "Flora Brasiliensis" de F. von Martius, o "Index Kewensis", "Dicionário de Plantas Úteis do Brasil", de M. Pio Corrêa, além de periódicos, livros, teses, separatas.

\section{Tipos nomenclaturais}

Parte importante do acervo do Herbário IBGE é sua coleção de tipos nomenclaturais. O Código Internacional de Nomenclatura Botânica (ICBN) rege os procedimentos para a atribuição de nomes aos diferentes grupos de plantas (e outros grupos de organismos tradicionalmente estudados pela Botânica - cianobactérias, fungos e algas), de modo que cada grupo (Família, Gênero, Espécie, Variedade, etc.) possua um único nome válido, internacionalmente aceito. No processo de descrição científica de um novo táxon, o nome proposto deve ser vinculado a um exemplar específico (ou fotografia ou ilustração, em casos excepcionais), de modo a evitar ambiguidades na relação entre 
o nome e os organismos a que se refere. A preservação e acessibilidade dos tipos nomenclaturais em coleções científicas são imprescindíveis para a missão da Taxonomia de descrever e catalogar as diferentes espécies de seres vivos.

Os tipos nomenclaturais são classificados em diferentes categorias, dependendo das circunstâncias em que foram designados. Um holótipo é um único espécime designado pelo autor original entre aqueles examinados no trabalho de descrição. Caso a publicação original não tenha designado um exemplar em particular como holótipo (o que ocorria frequentemente antes da adoção de regras explícitas sobre a designação de exemplares tipo pelo ICBN, em 1990), todos os exemplares citados na descrição são considerados síntipos, até que, em outro trabalho posterior, um dos síntipos seja designado como lectótipo. Na eventualidade do material citado originalmente se perder ou ser destruído, um novo exemplar de referência pode ser escolhido, e este se torna um neótipo. Em algumas situações um exemplar adicional pode ser necessário (por exemplo quando o holótipo, lectótipo ou neótipo não apresenta alguma estrutura morfológica de importância taxonômica), e então este exemplar complementar ganha o status de epítipo. Os demais espécimes examinados no trabalho de descrição são categorizados como parátipos. Duplicatas (ou seja, outras amostras da mesma espécie obtidas na mesma data e localidade e com o mesmo número de coleta - ex. vários ramos coletados de uma mesma árvore) de um exemplar recebem diferentes denominações, dependendo da categoria: isótipo no caso das duplicatas de um holótipo, nas demais categorias se adiciona o prefixo iso como em isolectótipo ou isoparátipo.

O Herbário IBGE abriga atualmente 355 exemplares tipo (Tabela 1 e Figura 2), referentes a 182 espécies e 3 variedades. Essas espécies estão distribuídas em 45 famílias, todas de angiospermas, sendo Poaceae, Eriocaulaceae e Fabaceae as mais representativas (97, 38 e 28 espécies, respectivamente). Assim como observado na coleção em geral, os tipos presentes no Herbário IBGE também se concentram principalmente no bioma Cerrado (Mapa 2). 


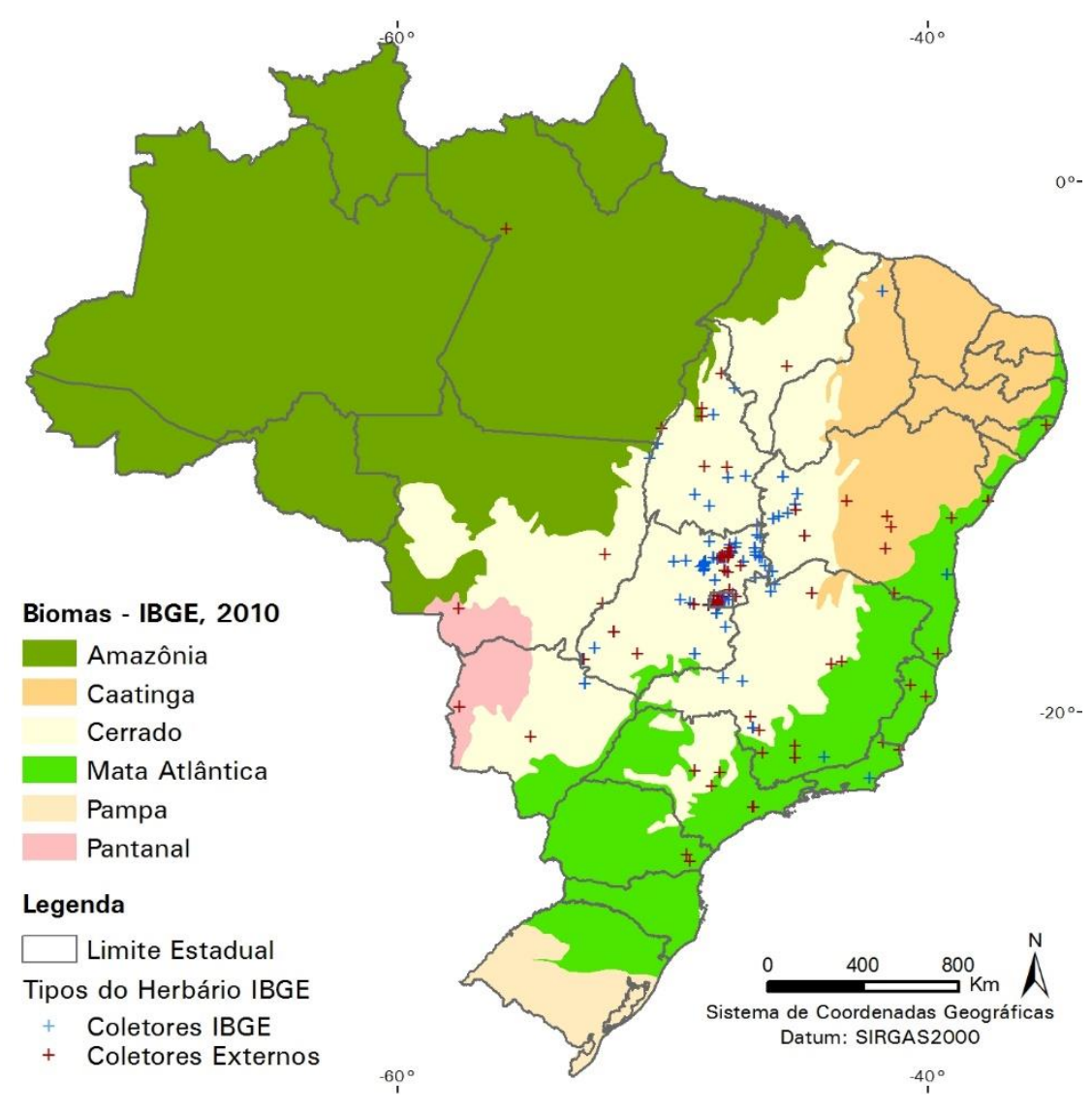

Mapa 2. Distribuição dos pontos de coletas dos tipos nomenclaturais do Herbário IBGE, por bioma, com destaque para as coletas da equipe IBGE, relativamente aos coletores externos.

A presença de material tipo em um herbário evidencia sua importância de diferentes maneiras. Uma delas diz respeito aos espécimes que estão na coleção por terem sido originalmente depositados ali, o que é o caso, por exemplo, dos 247 exemplares que foram coletados por membros da equipe do IBGE (70\% dos tipos do Herbário). Esse material atesta a contribuição do Herbário IBGE em inventariar a flora de áreas amplamente distribuídas no Cerrado. Outra contribuição é evidenciada na coleção de tipos através das 24 espécies (13\%) que foram descritas por pesquisadores do IBGE. Finalmente, há também os casos em que a espécie foi coletada e descrita por outros Herbários e o material tipo foi doado ao Herbário IBGE, por ser considerado uma coleção importante para determinada família. Exemplo disso é o holotipo de Arthropogon scaber Pilg. \& Kuhlm., coletado em Cáceres, MT, por FC Hoehne, em 1909 e doada ao Herbário IBGE pelo Herbário R (Museu Nacional do Rio de Janeiro). A descrição original dessa espécie foi publicada por Pilger e Kuhlman (1922). 


\begin{tabular}{|l|r|}
\hline Holotipos e Isótipos & 95 \\
\hline Lectótipos e Isolectótipos & 5 \\
\hline Neótipos & 1 \\
\hline Síntipos e Isosíntipos & 3 \\
\hline $\begin{array}{l}\text { Parátipos e demais } \\
\text { categorias }\end{array}$ \\
\hline Total & 251 \\
\hline
\end{tabular}

Tabela 1. Número de tipos nomenclaturais por categoria, no acervo do Hebário IBGE
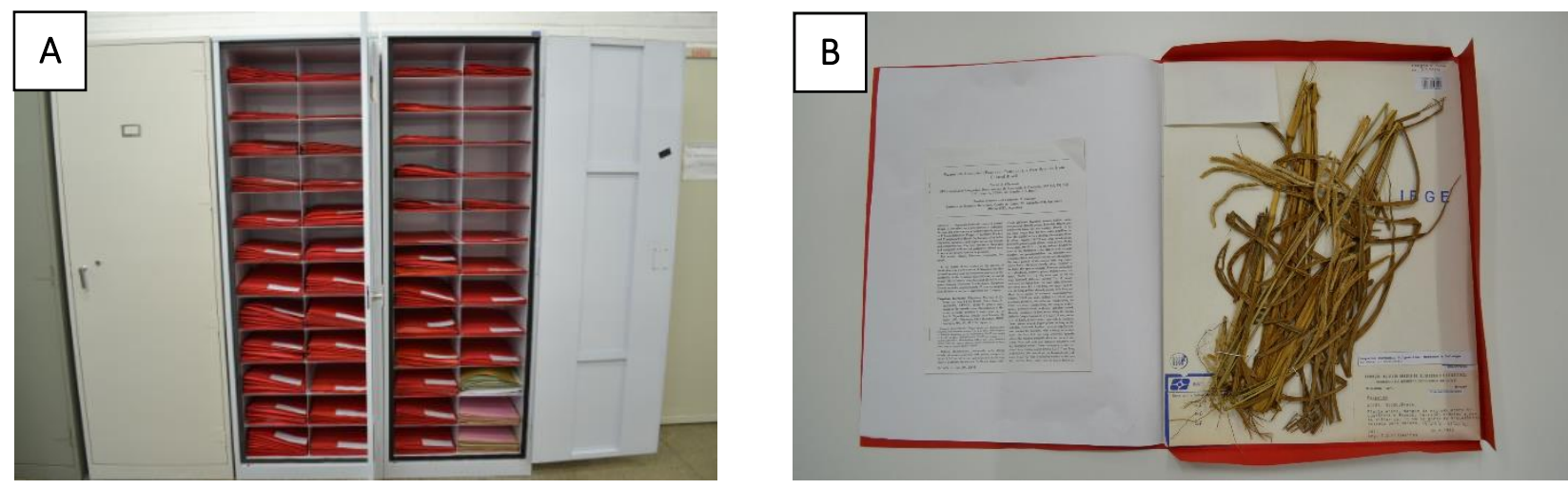

Figura 2. Armários dos tipos nomenclaturais (A), Holótipo de Paspalum burmanii Filg., Morrone \& Zuloaga acompanhado da publicação em que a espécie foi descrita.

\section{Intercâmbio}

O conhecimento da biodiversidade contida no acervo cresce graças à dedicação da equipe e também, fundamentalmente, à parceria eficiente e dinâmica com outras instituições. A identificação taxonômica é feita pelos técnicos do IBGE, pesquisadores visitantes e também por aqueles pesquisadores que tem acesso ao material quando enviado a outras instituições (empréstimo, doações ou permutas). Em seus mais de 40 anos de existência, o Herbário IBGE manteve sua diretriz de máximo compartilhamento dentro da rede de Herbários, com todas as amostras duplicadas distribuídas para outros herbários, totalizando ao longo da sua história mais de 100 mil eventos de intercâmbio de determinação tendo como princípio a difusão ativa das determinações realizadas em seu acervo (Gráfico 2). Merece destaque a cooperação de mais de 400 taxonomistas de diversas instituições que sistematicamente contribuem para a correta identificação dos 
espécimes. O empréstimo de exsicatas também é crucial no trabalho de identificação. As identificações recebidas sempre constam nas exsicatas e no banco de dados.

Gráfico 2. Intercâmbio de material botânico (a) e de determinações taxonômicas (b) entre o Herbário IBGE e outros herbários nacionais e internacionais ao longo de 41 anos - 1977 - 2018. Número de exsicatas enviadas (E) e recebidas (R).
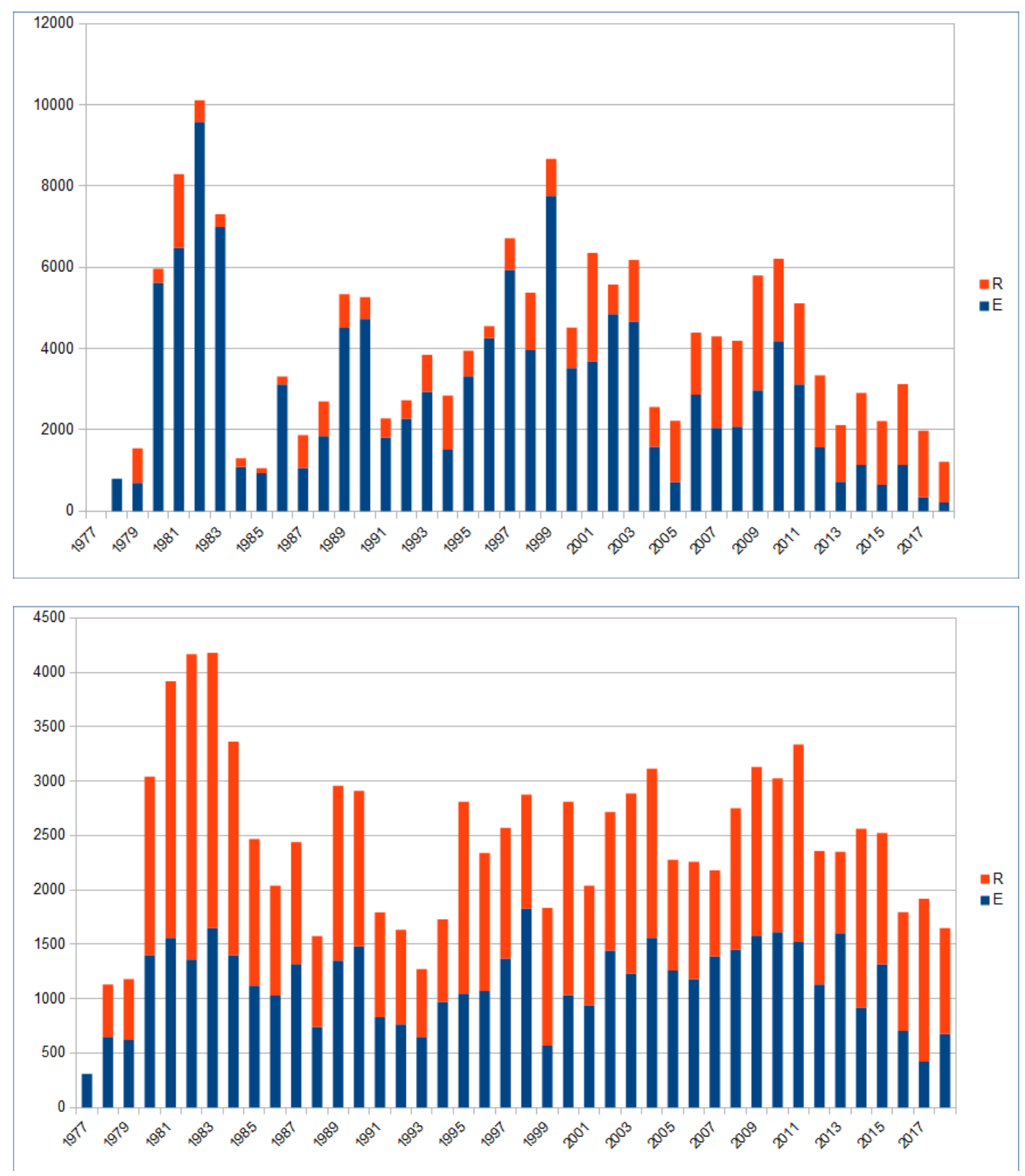

Atualmente o Herbário IBGE tem parceria com 174 herbários, distribuídos por todo o país e abrangendo, também, os 5 continentes do planeta. A maior parte, 95, vincula-se a instituições de pesquisa, distribuídas por 27 países (Mapa 3). De modo especial, destacamos os herbários da Inglaterra, França e Estados Unidos, que reúnem especialistas em diversas famílias botânicas, mantendo a tradição de identificar o material recebido de inúmeros herbários e centros de pesquisa 
de todo o mundo. Além disso, esses grandes herbários salvaguardam espécimes da flora brasileira coletados há mais um século pelos famosos naturalistas que percorreram extensa área do território nacional, descrevendo detalhes da paisagem e identificando plantas, muitas das quais sendo as primeiras descrições de espécies.

É interessante constatar que os herbários nacionais também representam praticamente todos os estados brasileiros, marcando presença nas 5 regiões do país.

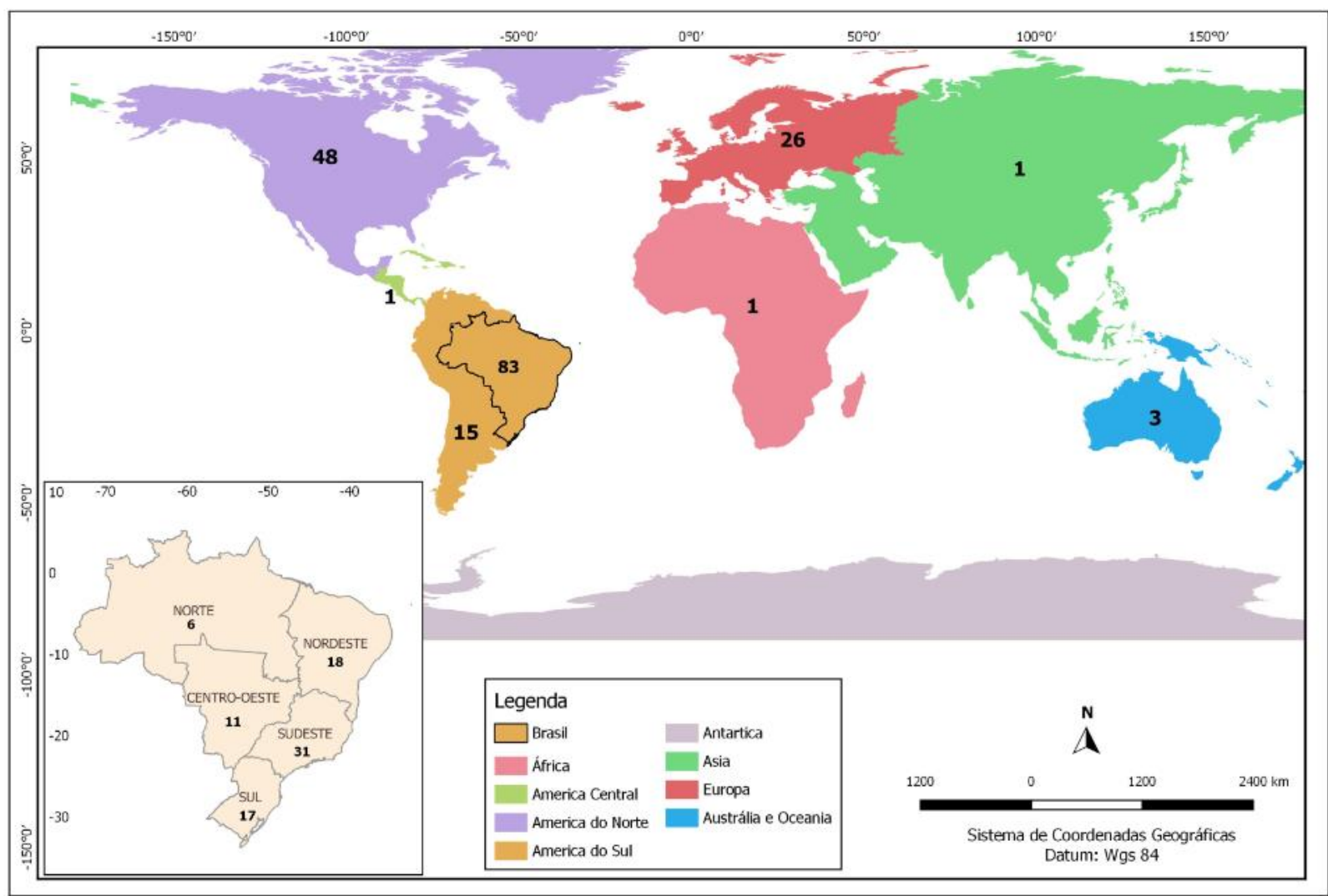

Mapa 3. Número de herbários que mantém intercâmbio com o Herbário IBGE por regiões do Brasil e do mundo

As diversas modalidades e exemplos de parcerias interinstitucionais aqui citadas além de propiciarem a geração e ampliação do conhecimento, imprimem maior credibilidade aos acervos que delas participam.

\section{Disseminação e Informação}

O acesso aos acervos científicos do IBGE pode ser presencial e também remoto. Para as visitas presenciais o Herbário IBGE é aberto ao público, de segunda a quinta feira, entre 08:30h e 16:30h. Os visitantes mais frequentes são pesquisadores, docentes nacionais e internacionais e demais segmentos da sociedade que necessitam de informações sobre a flora regional. Esse público 
recebe apoio técnico, científico e logístico dentro da infraestrutura da Reserva Ecológica do IBGE, onde se localiza o herbário. Entre 1992 e 2018, mais de 1000 pessoas - a maioria pesquisadores e estudantes de graduação e pós-graduação - visitaram o acervo (Gráfico 3).

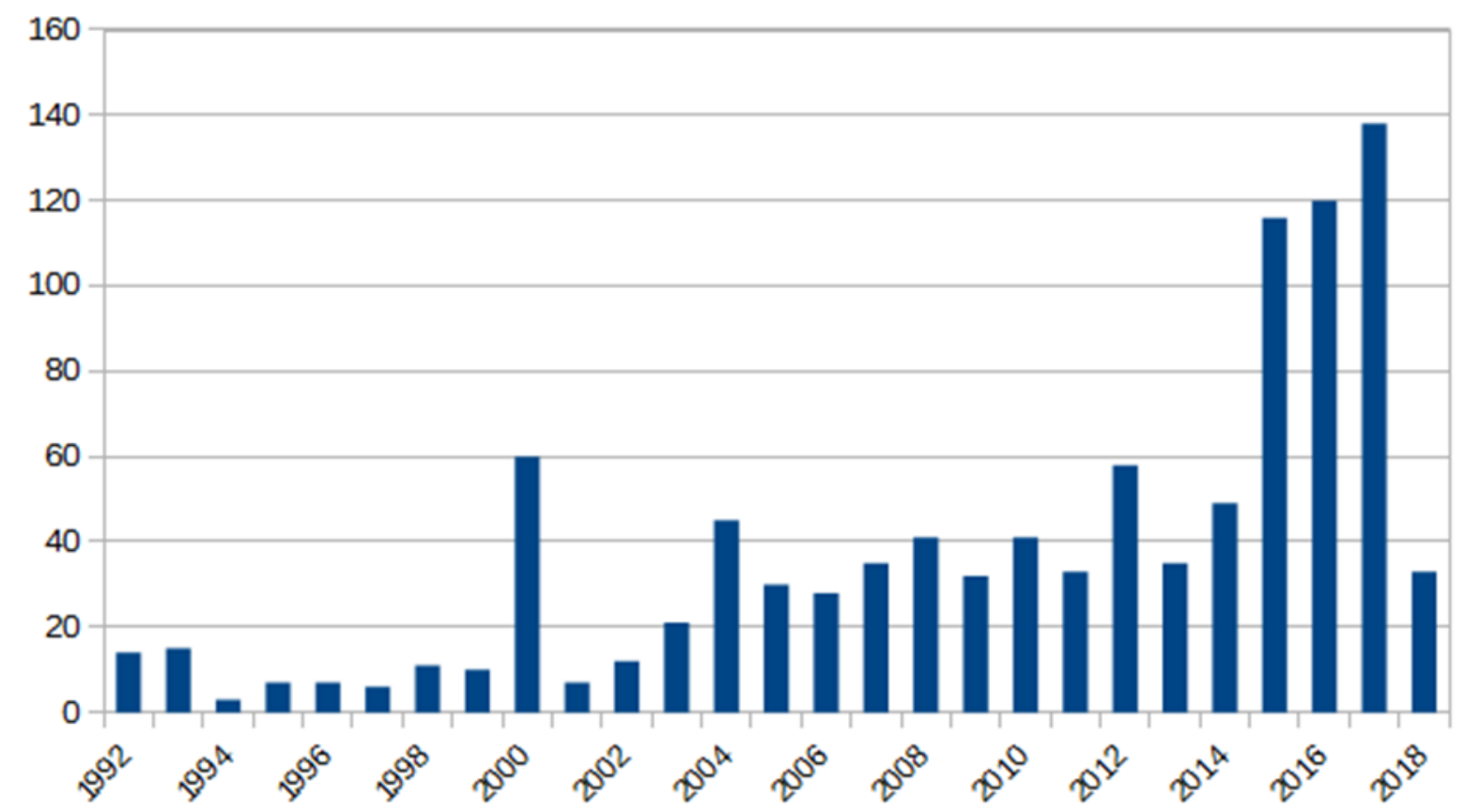

Gráfico 3. Número de visitas recebidas pelo Herbário IBGE. 1992-2018.

As consultas remotas têm sido viabilizadas pelo desenvolvimento de bancos de dados disponibilizados online. Esses esforços iniciaram-se ainda na década de 90, com o objetivo de promover o compartilhamento das informações e facilitar o acesso à coleção pelos usuários externos. Os dados foram inicialmente informatizados em bancos de dados locais e posteriormente em um sistema próprio desenvolvido pelo IBGE. Mais recentemente, fruto da cooperação técnica entre o IBGE e o Instituto Jardim Botânico do Rio de Janeiro, foi adotado o Sistema JABOT. Esse sistema possui ferramentas para gestão e publicação dos dados dos exemplares, além de facilidades para a importação de dados de campo, geração de etiquetas e controle do intercâmbio de material, otimizando as rotinas de manejo do Herbário. Atualmente cerca de $90 \%$ do acervo já encontra-se facilmente acessível através da internet, no endereço ibge.jbrj.gov.br (Figura 3). 

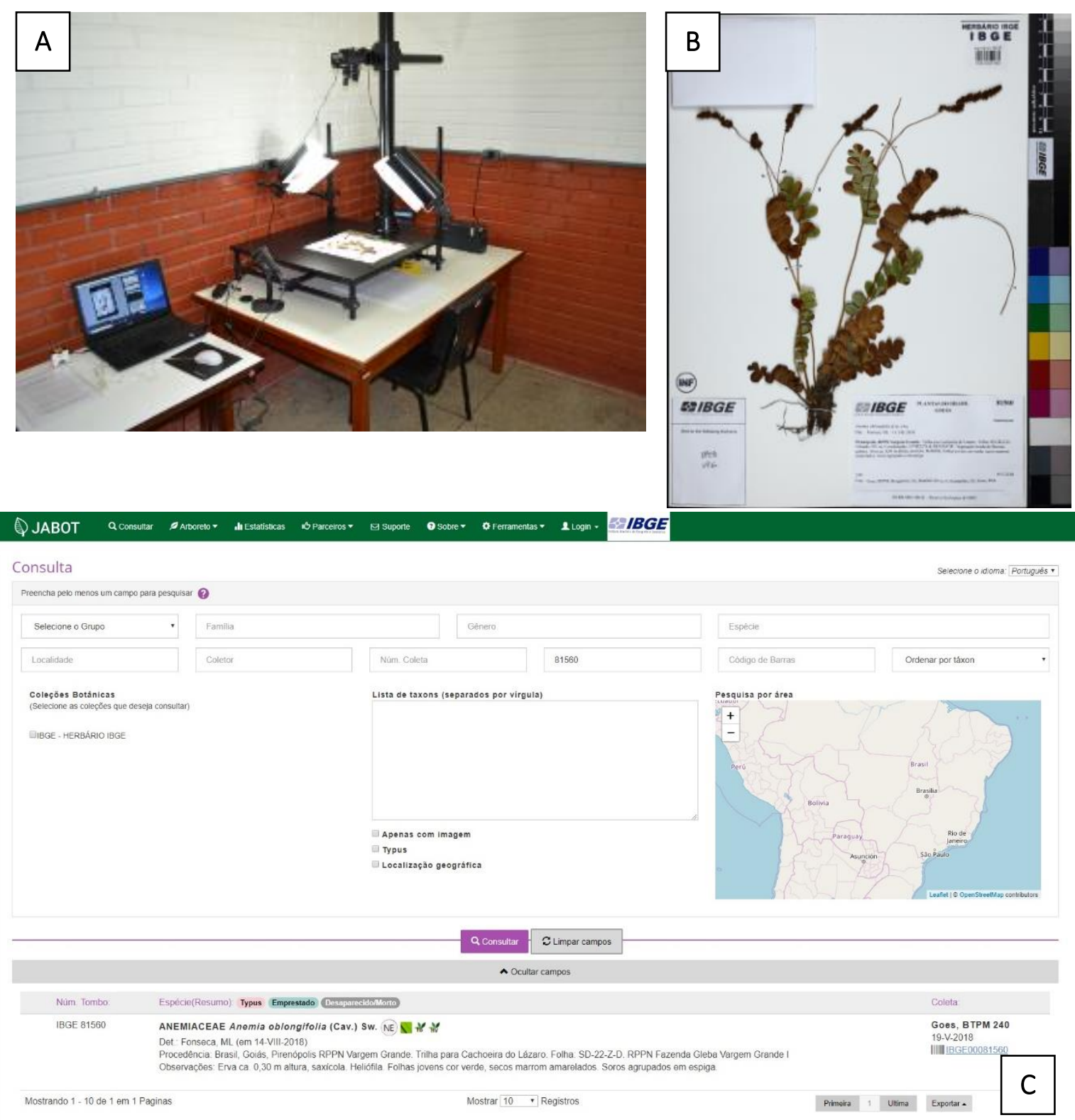

Figura 3. Estação fotográfica do Programa Reflora (A), imagem de um exemplar do acervo, pronta para publicação (B), tela do módulo de consulta pública do sistema Jabot (C).

O próximo passo na disponibilização das informações produzidas pelo Herbário IBGE será a captura e publicação de imagens em alta resolução das exsicatas, permitindo conferência dos dados informatizados com os dados das etiquetas, bem como a examinação remota dos exemplares por pesquisadores. Essa atividade está vinculada ao Programa Reflora/CNPq, que teve início com resgate das informações dos espécimes da flora brasileira depositados nos herbários estrangeiros, e foi estendida aos herbários nacionais para a construção do Herbário Virtual.

Outra parte integrante desse programa é o sistema Flora do Brasil 2020 que "funciona como um validador para os nomes atribuídos às imagens do Herbário Virtual Reflora, que também será 
atualizado e enriquecido por taxonomistas trabalhando, em rede, em um sistema online" (http://reflora.jbrj.gov.br, Acesso em 08 Ago. 2019).

A participação do Herbário IBGE nesse esforço nacional contribui para o cumprimento da primeira meta da Estratégia Global para a Conservação de Plantas (GSPC-CDB) para 2020, que compreende a elaboração, com acesso online, da Flora do Brasil Monografada 3 .

\section{Participação do Herbário IBGE na descrição da flora do Cerrado e do Brasil}

O Brasil é um dos 17 países designados megadiversos, que, juntos, concentram mais de $70 \%$ da biodiversidade conhecida (Mittermeier et al., 1997). Sua megadiversidade é bem exemplificada pela exuberância de sua flora, que apresenta a maior riqueza florística do mundo (mais de 32000 espécies de angiospermas, além de mais de 14000 espécies de outros grupos da flora, incluindo algas, briófitas, fungos, gimnospermas, samambaias e licófitas, BFG 2015) e a maior proporção de espécies endêmicas na América do Sul (57\%, BFG, 2015). A grande riqueza ambiental do país tornou natural a sua posição de liderança assumida nos fóruns internacionais, principalmente naqueles ligados à biodiversidade. A Convenção sobre Diversidade Biológica (CDB) tem se tornado, desde a Conferência das Nações Unidas sobre o Meio Ambiente e Desenvolvimento (ECO 92), um dos principais instrumentos internacionais relacionados às questões ambientais e o principal fórum internacional na definição do marco legal e político para temas relativos a biodiversidade e para várias convenções e acordos ambientais mais específicos.

A CDB assume três objetivos principais: a conservação da diversidade biológica (ou biodiversidade), o seu uso sustentável e a distribuição justa e equitativa dos benefícios decorrentes do uso econômico dos recursos genéticos, respeitada a soberania de cada nação sobre o patrimônio existente em seu território. Um dos programas estabelecidos no âmbito da CDB é a Estratégia Global para a Conservação de Plantas (GSPC-CDB) que busca fomentar o trabalho colaborativo em diferentes níveis (local, nacional, regional e global) para compreender, conservar e usar de modo sustentável a diversidade de plantas, além de promover a conscientização e a capacitação necessárias para isso. A Meta 1 da GSPC-CDB previa a publicação de um catálogo das espécies conhecidas de plantas e fungos em 2010 e a divulgação de descrições, chaves de identificação e ilustrações para todas as espécies de plantas, algas e fungos conhecidos para o país até 2020.

Em virtude das dimensões e diversidade do Brasil o cumprimento das metas estabelecidas na GSPC-CDB tem sido um grande desafio. Sua primeira etapa, finalizada em 2010 sob a coordenação do Jardim Botânico do Rio de Janeiro, levou à publicação do Catálogo de Plantas e

\footnotetext{
${ }^{3}$ Disponível em: <www.reflora.jbrj.gov.br>. Acesso em: 8 ago. 2019.
} 
Fungos do Brasil (disponível em http://dspace.jbrj.gov.br/jspui/handle/doc/35), construído com o trabalho colaborativo de mais de 400 taxonomistas (BFG 2018). Nessa linha de atuação, o Herbário IBGE participou da organização da lista de plantas vasculares do bioma Cerrado (Mendonça, RC et al, 2008), em parceria com a EMBRAPA e pesquisadores Universidade de Brasília. Esse trabalho foi publicado no livro Cerrado: Ecologia e Flora, que apresentou um checklist com 12.356 espécies do bioma. Esse trabalho exigiu um esforço monumental da equipe, envolvendo também revisão taxônomicas de grupos específicos, manuseio de listas e catálogos de espécies, consultas a inúmeros artigos científicos e publicações nacionais e internacionais além dos levantamentos complementares de herbário.

Mais recentemente a adoção de novas tecnologias para a compilação e divulgação da flora online facilitou o trabalho remoto e a atualização constante da lista de espécies de plantas, algas e fungos do Brasil, que está disponível para ampla consulta em (http://floradobrasil.jbrj.gov.br) e é facilmente exportada para usos externos através do formato de dados Darwin Core Archive (padrão de dados para compartilhamento de dados sobre biodiversidade amplamente utilizado).

Atualmente os esforços se concentram na preparação das descrições morfológicas, chaves e ilustrações das mais de 46000 espécies de plantas reconhecidas para o Brazil (BFG 2018). Esse trabalho está sendo desenvolvido com a colaboração de mais de 700 taxonomistas, que preenchem as informações detalhadas sobre cada táxon. A seleção dos responsáveis se dá através de um processo de chamada pública, em que os grupos de plantas disponíveis são apresentados e os pesquisadores se candidatam para verificar e descrever os mesmos. Em 2018 a maior parte das Angiospermas, Gimnospermas, Briófitas, Samambaias e Licófitas já estavam atribuídas a algum colaborador (Gráfico 4). Por outro lado, há uma carência maior em relação às Algas e Fungos, reflexo do número proporcionalmente menor de taxonomistas atuando nesses grupos.

O material de referência depositado nos Herbários é fundamental para a compilação das listas e para as descrições detalhadas que estão sendo preparadas. Em 2018 exemplares do acervo do Herbário IBGE contavam com mais de 900 citações na Flora do Brasil, distribuídas entre 90 famílias de Angiospermas e 4 famílias de Pteridófitas. A maior parte das citações se concentra nas famílias Poaceae (com 208 citações), Asteraceae (98 citações) e Fabaceae (82 citações). Essa distribuição de citações reflete, por um lado, a ampla representatividade da coleção (que é o caso da coleção de Poaceae do Herbário IBGE, que contempla mais de $90 \%$ dos gêneros e cerca de $60 \%$ das espécies presentes no Brasil) e por outro, a alta diversidade de algumas famílias no Cerrado, (caso de Asteraceae e Fabaceae), uma vez que as coletas da equipe são amplamente distribuídas pelo bioma. 


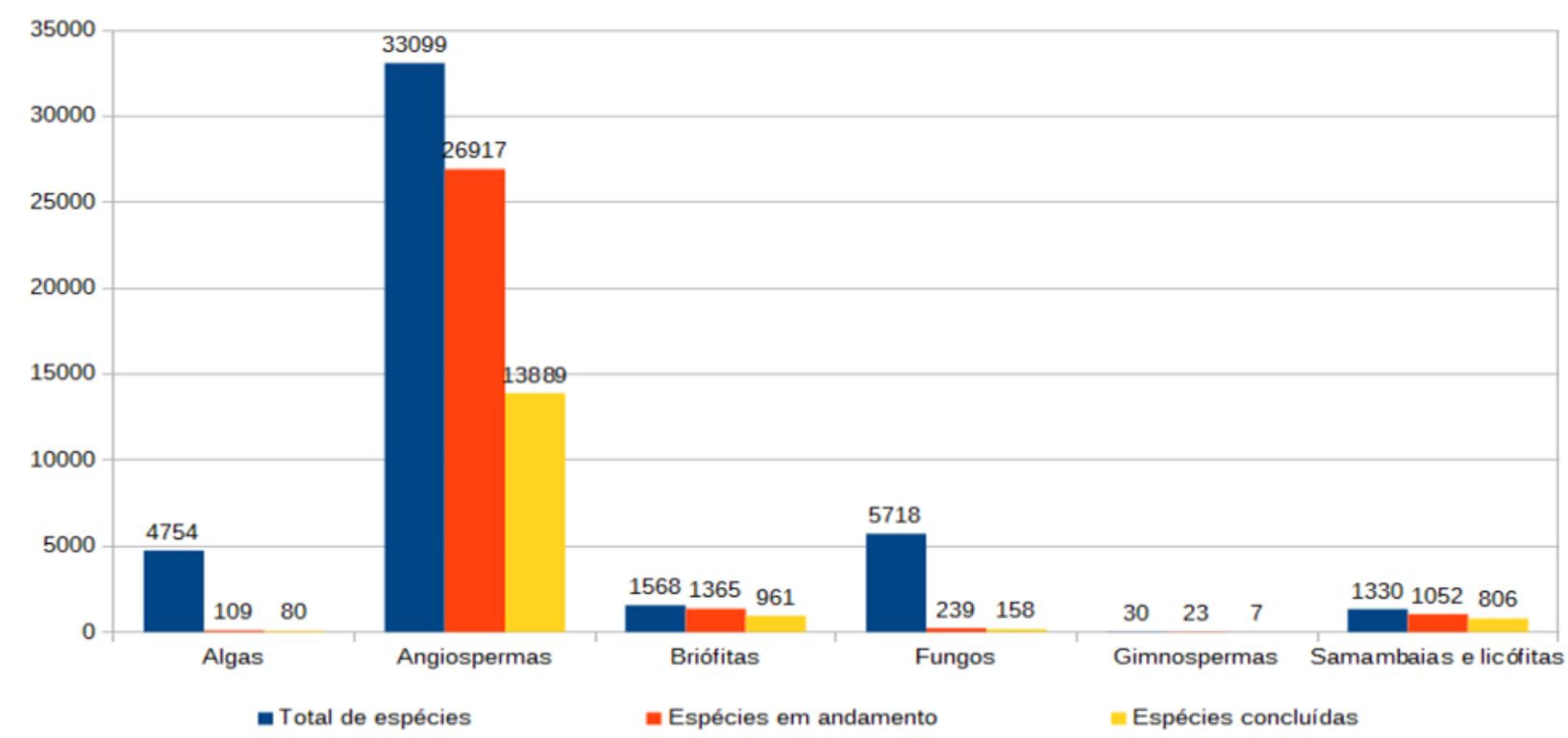

Gráfico 4. Número de espécies, por grupo, reconhecidas para o Brazil (barra azul), atribuídas a algum taxonomista para descrição no Flora 2020 (barra vermelha), e com suas monografias concluídas (barra amarela). Traduzido e adaptado de BFG (2018).

Embora a organização e compartilhamento eficiente dessas bases seja um grande desafio, considerando o tamanho do país e o número de instituições e pesquisadores envolvidos, os benefícios são reconhecidamente inestimáveis. Além de otimizar a aplicação de esforços e recursos, a integração dos bancos de dados, pode aprimorar os diagnósticos sobre o estado atual da biodiversidade, a aferição de alcance das Metas Nacionais de Biodiversidade e a projeção de cenários que ajudem a analisar de forma mais profunda as relações entre os processos socioeconômicos e de gestão ambiental amparando as tomadas de decisões nos mais diferentes níveis.

No decorrer desses mais de 40 anos, o Herbário IBGE integra esse esforço contínuo de levantamento e compartilhamento de informações e dados e reconhece que há ainda mais trabalho a ser realizado. A equipe tem voltado sua atenção, nos últimos anos, para as áreas pouco coletadas do bioma Cerrado e espera continuar atraindo para seu acervo o interesse sempre prestativo dos seus parceiros e de todas as pessoas interessadas em conhecer a rica biodiversidade brasileira.

Agradecimentos

Agradecemos à Alessandra Luiza Gouveia pela confecção dos mapas e a todos que se dedicaram à construção e manutenção do Herbário IBGE em seus mais de 40 anos de história: servidores, pesquisadores, coletores, estudantes, estagiários, colaboradores e 
Referências

ALBELÁEZ-CORTÉS, E.; ACOSTA-GALVIS, A. R.; DONASCIMIENTO, C.; ESPITIA-REINA, D.; GOZÁLEZ-ALVARADO, A.; MEDINA, C. A. Knowledge linked to museum specimen vouchers: measuring scientific production from a major biological collection in Colombia. Scienciometrics, v.112, n.3, pp 1323-1341, 2017.

ANGIOSPERM PHYLOGENY GROUP. An update of the Angiosperm Phylogeny Group classification for the orders and families of flowering plants: APG IV. Botanical Journal of the Linnean Society, v.181, n.1, pp.1-20, 2016.

BINGHAM, H. C.; et al. The biodiversity informatics landscape: elements, connections and opportunities. Research Ideas and Outcomes, v.3, e14059, 2017.

BARTOMEUS, I.; STAVERT, J. R.; WARD, D.; AGUADO, O. Historical collections as a tool for assessing the global pollination crisis. Philosophical Transactions of the Royal Society $B$, v.374, 20170389, 2018.

BEAULIEU, C.; LAVOIE, C.; PROULX, R. Bookkeeping of insect herbivory trends in herbarium specimens of purple loosestrife (Lythrum salicaria). Philosophical Transactions of the Royal Society B, v.374, 20170398, 2018.

BEBBER, D. P.; et al. Herbaria are a major frontier for species discovery. PNAS, v. 107, n. 51, 2010.

BFG - THE BRAZILIAN FLORA GROUP. Growing knowledge: an overview of seed plant diversity in Brazil. Rodriguésia, v.66, n.4, 2015.

BFG - THE BRAZILIAN FLORA GROUP. Brazilian Flora 2020: Innovation and collaboration to meet Target 1 of the Global Strategy for Plant Conservation (GSPC). Rodriguésia, v.69, n.4, 15131527, 2018.

BRASIL. Lei $n^{\circ}$ 5.878, de 11 de maio de 1973. Dispõe sobre a Fundação Instituto Brasileiro de Geografia e Estatística - IBGE, e dá outras providências, Brasília, DF, julho de 2019.

CRUTZEN, P. J.; STOERMER, E. F. The "Anthropocene". Global Change Newsletter, v.41, pp.17$18,2000$.

ESCRIBANO, N.; GALICIA, D.; ARINO, A. H. The tragedy of the biodiversity data commons: a data impediment creeping nigher? Database, doi:10.1093/database/bay033, 2018.

FERRIER, S. Mapping spatial pattern in Biodiversity for regional conservation planning: where to from here? Systematic Biology, v.51, pp.331-363, 2002.

FONSECA, M. L.; GUIMARÃES, L. L. 2011, Coleções biológicas da biota terrestre. In: IBGE. 2011. Reserva Ecológica do IBGE: biodiversidade terrestre. Organizador: Mauro César Lambert de Brito Ribeiro. Rio de Janeiro: IBGE.

FONSECA, M. L.; GUIMARÃES, L. L. Herbário da Reserva Ecológica do IBGE, Distrito Federal (IBGE). UNISANTA Bioscience, v.4, n.6, pp. 20-23, 2015. 
GRAHAM, C. H.; FERRIER, S.; HUETTMAN, F.; MORITZ, C.; PETERSON, A. T. New developments in museum-based informatics and applications in biodiversity analysis. Trends in Ecology and Evolution, v.19, n.9, 2004.

HOLMGREM, P. K.; KEUKEN, W. Additions to "Herbaria of the World" ed.6 (IV). Taxon, v.29, n.4, pp.519-532, 1980.

HOSKINS, A. J. et al. Supporting global biodiversity assessment through high-resolution macroecological modelling: Methodological underpinnings of the BILBI framework. bioRXiv, https://doi.org/10.1101/309377, 2019.

IPBES. Summary for policymakers of the regional assessment report on biodiversity and ecosystem services for the Americas of the Intergovernmental Science-Policy Platform on Biodiversity and Ecosystem Services. Rice, J. et al. (eds.). IPBES secretariat, Bonn, Germany, 2018.

JARDIM BOTÂNICO DO RIO DE JANEIRO. Disponível em: <http://reflora.jbrj.gov.br>. Acesso em: 8 ago. 2019.

JOST, T. Herbário RADAMBRASIL, Bahia (HRB). UNISANTA Bioscience, v.4, n.6, pp. 101-104, 2015.

KURY, A. B. et al. Diretrizes e estratégias para a modernização de coleções biológicas brasileiras e a consolidação de sistemas integrados de informação sobre biodiversidade. Brasília: Centro de Gestão e Estudos Estratégicos: Ministério da Ciência e Tecnologia, 2006.

LUGHADHA, E. N. et al. The use and misuse of herbarium specimens in evaluating plant extinction risks. Philosophical Transactions of the Royal Society B, v.374, 20170402, 2018.

MARINONI, L.; PEIXOTO, A. L. As coleções biológicas como fonte dinâmica e permanente de conhecimento sobre a biodiversidade. Ciência e Cultura, v.62, pp54-57, São Paulo, 2010.

MCALLISTER, C. A.; MCKAIN, M. R.; LI, M.; BOOKOUT, B.; KELLOGG, E. A. Specimen-based analysis of morphology and the environment in ecologically dominant grasses: the power of the herbarium. Philosophical Transactions of the Royal Society B, v.374, 20170403, 2018.

MEINEKE, E. K.; DAVIES, T. J.; DARU, B. H.; DAVIS, C. C. Biological collections for understanding biodiversity in the Anthropocene. Philosophical Transactions of the Royal Society B, v.374, 20170386, 2018.

MENDONÇA, R. C. et al. Flora vascular do bioma Cerrado: checklist com 12.356 espécies. In: Sano, S. M.; Almeida, S. P.; RIBEIRO, J. F. (Ed.). Cerrado: Ecologia e Flora. Brasília, DF: Embrapa Informação Tecnológica; Planaltina, DF: Embrapa Cerrados, 2008. V 2, p. 421-442.

MILLENNIUM ASSESSMENT BOARD. Millenium ecosystem assessment. Washington, DC: New Island 13, 2005.

MITTERMEIER, R.A. et al. Megadiversity: Earth's biologically wealthiest nations. CEMEX and Agrupación Sierra Madre, 1997. 
NELSON, G.; ELLIS, S. The history and impact of digitization and digital data mobilization on biodiversity research. Philosophical Transactions of the Royal Society B, v.374, 20170391, 2018.

PARK, D. S.; BRECKHEIMER, I.; WILLIAMS, A. C.; LAW, E.; ELLISON, A. M.; DAVIS, C. C. Herbarium specimens reveal substantial and unexpected variation in phenological sensitivity across the eastern United States. Philosophical Transactions of the Royal Society B, v.374, 20170394, 2018.

PEREZ, T. M. et al. Botanic gardens are an untapped resource for studying the functional ecology of tropical plants. Philosophical Transactions of the Royal Society B, v.374, 20170390, 2018.

PILGER, R. K. F.; KUHLMANN, J. C. Título desonhecido. Commissão de Linhas Telegraphicas, Botanica 67(11), páginas 37 e 38.

PONDER, W. F.; CARTER, G. A.; FLEMONS, P.; CHAPMAN, R. R. Evaluation of museum collection data for use in biodiversity assessment. Conservation Biology, v.15, pp. 648-657, 2001.

RIBEIRO, M. C. L. B. 2011. In: IBGE. 2011. Reserva Ecológica do IBGE: biodiversidade terrestre. Organizador: Mauro César Lambert de Brito Ribeiro. Rio de Janeiro: IBGE.

SCHINDEL, D. E.; COOK, J. A. The next generation of natural history collections. PLoS Biology, v.16, n.7, e2006125, 2018.

SHAFFER, H. B.; FISHER, R. N.; DAVIDSON, C. The role of natural history collections in documenting species declines. Trends in Ecology and Evolution, v.13, n.1, 1998.

SOBRAL, M.; STEHMANN, J. R. An analysis of new angiosperm species discoveries in Brazil (19902006). Taxon, v.58, n.1, 2009.

WINKER, K.; WITHROW, J. J. Small collections make a big impact. Nature, v.493, 2013.

Observações sobre alguns pontos de vista geográficos. Boletim Geográfico v.22, n.179, 1964. 